\title{
BENDING CAPACITY OF BIAXIAL-HOLLOW RC SLAB WITH ASYMMETRIC STEEL BEAMS
}

\author{
Chao Gong ${ }^{1}$, Zhao-Xin Hou ${ }^{1}$, Guo-Zhong Cheng ${ }^{2, *}$, Gang Wang ${ }^{1}$ and Y. Frank Chen ${ }^{2}$ \\ ${ }^{1}$ Central Research Institute of Building and Construction Co., Ltd, Beijing 100088, China. \\ ${ }^{2}$ Key Laboratory of New Technology for Construction of Cities in Mountain Area (Chongqing University), Ministry of Education, Chongqing 400045, China \\ *(Corresponding author: E-mail:chengguozhong@cqu.edu.cn)
}

\section{A B S T R A C T}

A new composite slim floor system with voided RC slab is proposed, where the precast RC slab is used as the structural component as well as the permanent formwork, with the large voids achieved by light-weight fillers introduced to reduce the slab weight. The overlapping rebars pass through the web openings of steel beam, thus enhancing the interaction between the RC slab and steel beam. As a pilot study of the proposed floor system, the bending behavior of the new composite slim beam was investigated experimentally on four specimens. The full interaction between the RC slab and steel beam is demonstrated by the test and finite element analysis results. In addition, a calculation method for bending capacity is proposed.
ART I CLE H IST ORY

$\begin{array}{ll}\text { Received: } & 21 \text { September } 2019 \\ \text { Revised: } & 29 \text { July } 2020 \\ \text { Accepted: } & 10 \text { August } 2020\end{array}$

\section{K E Y W O R D S}

Composite slim floor

Biaxial-hollow slab;

Asymmetric steel beam;

Bending capacity.

\section{Introduction}

A variety of composite floor systems have been proposed and used for buildings throughout the world [1-4]. Among them, the composite floor system with the H-shaped steel beam and reinforced concrete (RC) slab (Fig. 1(a)) has been commonly used in building structures [5,6]. The presence of RC slab increases the lateral stability and bending capacity of $\mathrm{H}$-shaped beam and the profiled steel deck serves as the permanent formwork, resulting in a simpler construction process. However, such composite floor system has a larger depth than a typical RC beam as the steel deck needs to be set at the top flange of steel beam. Besides, it requires additional fire protection materials. To decrease the overall depth of floor systems in multi-story buildings, a composite slim floor system has been first developed in Scandinavia and then widely used in Europe and the United States [7,8]. In this system (Fig. 1(b)), an asymmetric steel beam with a wider bottom flange is used, where the deep steel deck is set at the bottom flange of the steel beam. As such, the steel beam is mostly contained within the depth of RC slab, resulting in a solid flat slab appearance similar to the RC construction that requires minimal fire protection $[9,10]$. Besides, the concrete surrounding the steel beam increases the bending capacity and local buckling strength of the steel beam. Therefore, the composite slim floor system is considered as a good alternative to the traditional floor system.

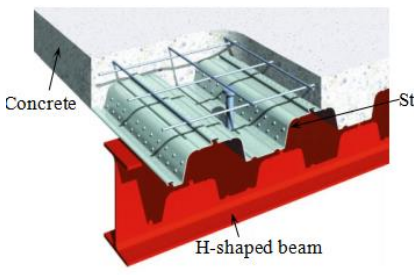

(a) Composite floor system

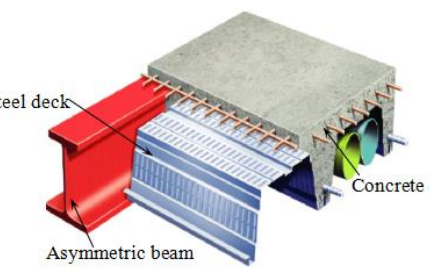

(b) Composite slim floor system
Fig. 1 Composite beams

The composite slim floor system had been studied somewhat extensively in terms of the integration of the composite beam and the connection between the composite slim floor and the column. Research on nine composite slim beams had been conducted at Helsinki University of Technology [11]. Additionally, a study on the behavior of composite beam-to-column connections had also been made at Helsinki University of Technology [12]. To investigate the influences of reinforcement ratio and load condition on the behavior of composite slim beams, experiments on eight specimens had been conducted at Trento University [13], in which the experimental results showed that the reinforcement ratio had a significant influence on the loading capacity of composite connections. The design of composite slim beams depends mainly on the shear transfer mechanism provided by the shear connectors between the RC slab and steel beam and a good number of studies on the behavior of shear connectors in such members had been conducted [14,15]. The available experimental results indicated that the interface slippage between the concrete slab and steel beam could be neglected. Besides the structural behavior, a holistic research had also been conducted on the fire resistance of composite slim floor systems $[16,17]$. In the composite slim floor system, deep decks are commonly used. Decks deeper than $200 \mathrm{~mm}$ may not be available in every place including China. Besides, the deeper decks need to be protected from corrosion, thus increasing the cost. Moreover, the traditional composite slim floor system is not suitable for moment resistance due to the semi-rigid connections between beams and columns. Therefore, the traditional composite slim floor system is not widely used in China. For improvement, a new composite floor system (Fig. 2) has been proposed by the researchers at Korea University, where the circular openings in the steel web enable the transverse reinforcements to pass through the beam, making the moment-resisting frame suitable. A number of spheres are introduced to reduce the weight of RC slab. The Glass Fiber Reinforced Plastic (GFRP) plate, which is attached to the bottom flange of the steel beam, acts as a structural reinforcement as well as a good heat insulator. A series of studies on the structural behavior of the new composite beam have been conducted at Korea University [18-20]. However, in this system the steel deck is only used as the permanent formwork, which requires additional supports; and it is timeconsuming to place the numerous spheres in place.

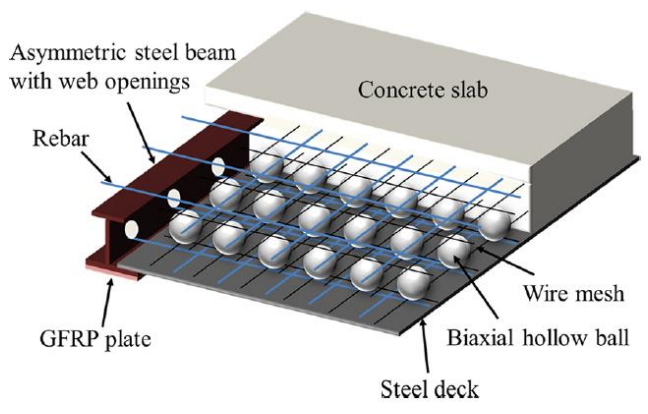

Fig. 2 The composite floor system proposed by Korea University

In this paper, a newer composite floor system, as shown in Fig. 3, is proposed to further improve the performance of existing composite slim floor systems. In this system, an asymmetric steel beam with web openings is used to reduce the depth of composite floor, similar to other composite slim floor systems. The overlapping rebars, which pass through the beam web openings, plus the shear studs enhance the integrity of composite floor. The stirrups are 
used to transfer the shear force between the precast RC slab and cast-in-place concrete. The precast RC slab is used as the structural component as well as the permanent formwork, which is more cost-effective. The large voids achieved by light-weight fillers are introduced to reduce the weight of RC slab, which can be easily installed in place. The bottom flange of steel beam is covered by the concrete for fire protection. A practical project adopting the new composite floor system is shown Fig. 4, which is a prefabricated building in Tangshan City (China). To investigate the flexural performance of the proposed floor system, four composite slim beams were tested.

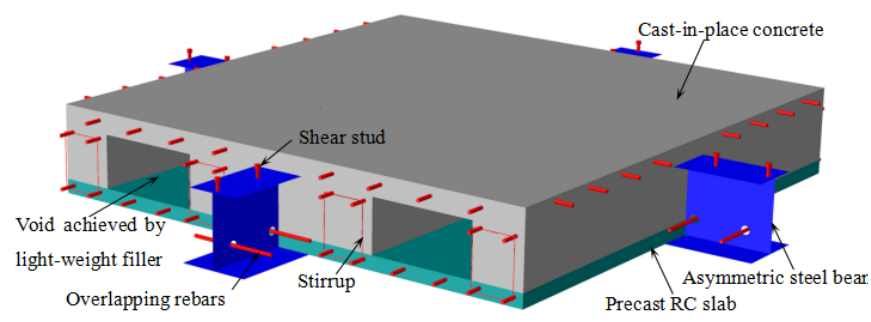

Fig. 3 Proposed composite floor system

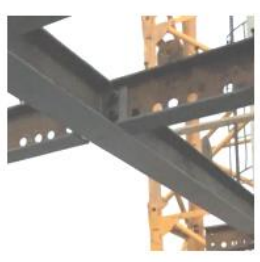

(a) Asymmetric steel beam with circular holes

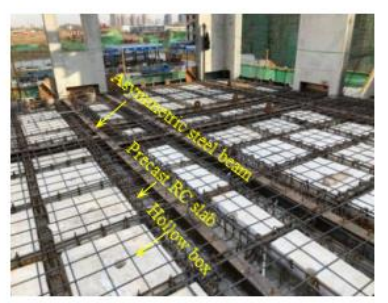

(c) Floor system under construction

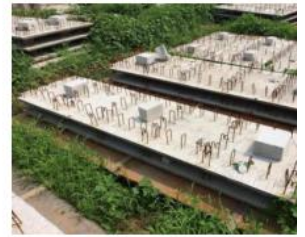

(b) Precast RC slab

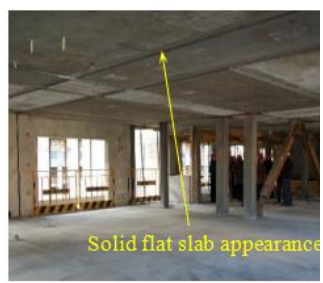

(d) Finished floor syste
Fig. 4 A practical project using the new composite floor system

\section{Experimental program}

\subsection{Description of specimens}

Four full-scale specimens were designed and tested in this study. Each specimen consists of the asymmetric steel beam, precast concrete, fillers, castin-place (CIP) concrete, and rebars. The fillers are made of light-weight expanded polystyrene boards. Fig. 5 shows the specimen' s cross-section and dimensions and Fig. 6 indicates the filler locations. As shown, the composite beam is typically $800 \mathrm{~mm}$ (width) $\times 270 \mathrm{~mm}$ (height) $\times 3900 \mathrm{~mm}$ (length). Two beam configurations were considered: Beam-T and Beam-C (Fig. 7). In Beam$\mathrm{T}$, each web trapezoidal opening acts as a shear connector, enhancing the interaction between the RC slab and steel beam. In Beam-C, both overlapping $14 \mathrm{~mm}$-diameter rebars and $10 \mathrm{~mm}$-diameter shear studs were used to transfer the shear force between the RC slab and steel beam, in which the overlapping rebars work as PBL (Perfo-Bond Leisten) shear connectors. In order to investigate the effect caused by the circular holes in Beam-C, the diameter of circular holes (d1) was taken as $36 \mathrm{~mm}$ for Specimen 3 and $60 \mathrm{~mm}$ for Specimen 4. Two different load conditions were considered: sagging moment and hogging moment (Fig. 8). The strength grade is C35 (compressive strength $=35 \mathrm{MPa}$ ) for the concrete, Q345B (yield stress $=345 \mathrm{MPa}$ ) for the steel, and HRB400 (yield stress $=400 \mathrm{MPa}$ ) for the rebars. The specimen details are specified in Table 1 and the material properties are listed in Tables 2 and 3.

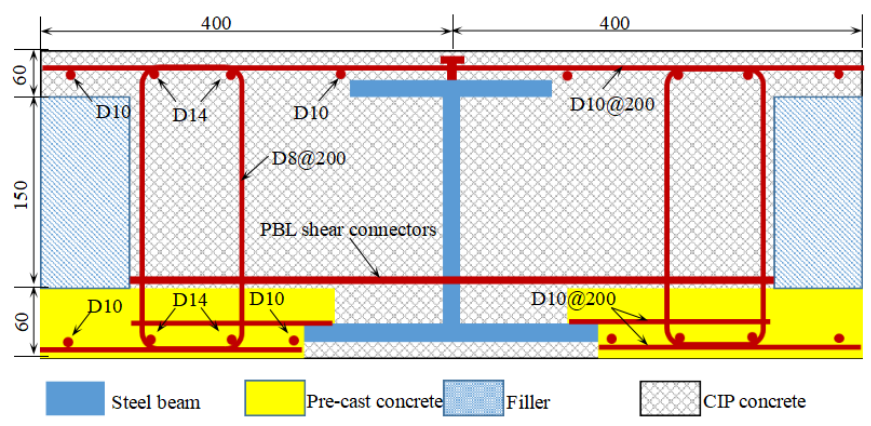

Fig. 5 Specimen cross-section and dimensions (in $\mathrm{mm}$ )

(Note: Dxx@yy denotes a bar with diameter xx and spacing yy, both in mm)

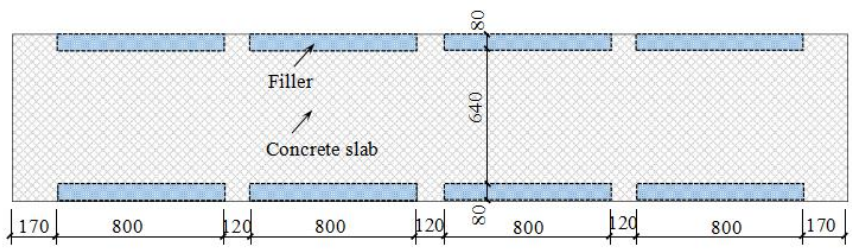

Fig. 6 Filler locations (dimensions in $\mathrm{mm}$ )

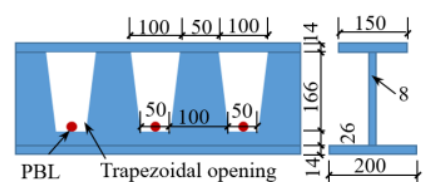

(a) Beam-T

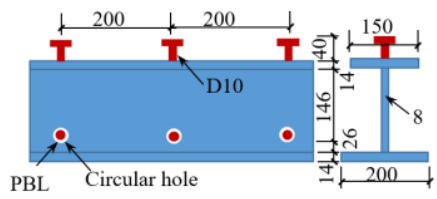

(b) Beam-C
Fig. 7 Details of the asymmetric steel beam (a) Sagging moment

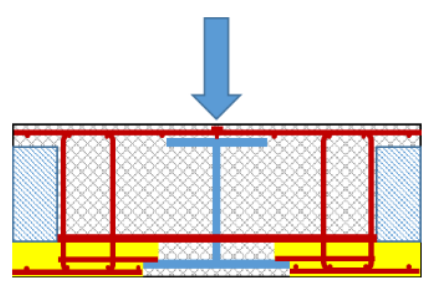

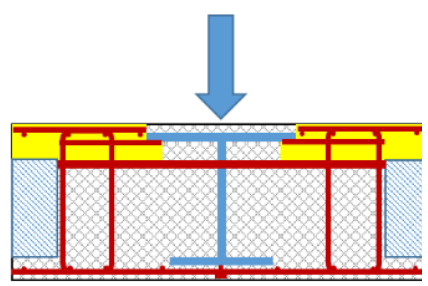

(b) Hogging moment
Fig. 8 Loading conditions

Table 1

Specimen details

\begin{tabular}{cccc}
\hline Specimen label & Type of beam & Loading condition & Diameter of circular hole \\
\hline Specimem-1 & Beam-T & Sagging moment & $/$ \\
Specimem-2 & Beam-C & Sagging moment & $d_{1}=36 \mathrm{~mm}$ \\
Specimem-3 & Beam-C & Hogging moment & $d_{1}=36 \mathrm{~mm}$ \\
Specimem-4 & Beam-C & Hogging moment & $d_{1}=60 \mathrm{~mm}$ \\
\hline
\end{tabular}

Table 2

The material properties of concrete

\begin{tabular}{cccc}
\hline Material & $f_{\text {cu, }}\left(\mathrm{N} / \mathrm{mm}^{2}\right)$ & $f_{\mathrm{c}}\left(\mathrm{N} / \mathrm{mm}^{2}\right)$ & $E\left(10^{3} \mathrm{~N} / \mathrm{mm}^{2}\right)$ \\
\hline Precast concrete & 40 & 33 & 32.6 \\
CIP concrete & 28.1 & 24.5 & 29.1 \\
\hline
\end{tabular}


Table 3

The material properties of steel and rebars

\begin{tabular}{ccc}
\hline Material & Yield strength $f_{\mathrm{y}}\left(\mathrm{N} / \mathrm{mm}^{2}\right)$ & Ultimate strength $f_{\mathrm{u}}\left(\mathrm{N} / \mathrm{mm}^{2}\right)$ \\
\hline T8 & 422 & 540 \\
T14 & 358 & 510 \\
D8 & 445 & 648 \\
D10 & 483 & 669 \\
D14 & 435 & 603 \\
\hline
\end{tabular}

\subsection{Test set-up}

Each specimen was simply supported and equally loaded at one-third points through the use of a 1000-kN jack, as shown in Fig. 9. The distance between the two supports is $3800 \mathrm{~mm}$. The specimens were set up to have a pure bending zone of $800 \mathrm{~mm}$ and a shear span to depth ratio of 5.6. The loading was applied using the load-controlled scheme with the loading rate of $5 \mathrm{kN} / \mathrm{min}$ for each load increment of $50 \mathrm{kN}$. Each load was retained for about 3 minutes to monitor the test data and to observe the cracks. When the load decreased to $85 \%$ of the peak load in the descending stage or when the crushing of concrete occurred, the specimen was considered a failure and the test was terminated.

The vertical load $(\mathrm{P})$ was monitored by a load cell. All displacements were measured by linear variable differential transformers (LVDTs), as shown in Fig. 9. The deformations during the loading process were measured by LVDTs 1-3 and the support settlements were recorded by LVDTs 5-6 in order to determine the net deformation at mid-span $\left(U_{\text {mid }}\right)$. The slippage between the RC slab and steel beam was monitored by LVDT 4 . The strain gauges were arranged on the steel beam, rebars, and concrete surface at the mid-span section (Section A-A, Fig. 9(a)), as shown in Fig. 10

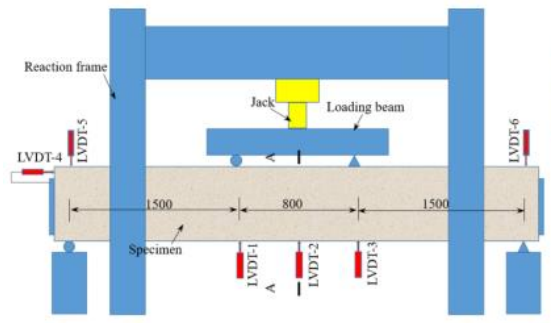

(a) sketch

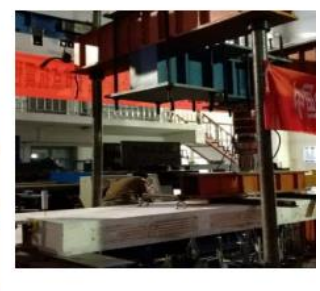

(b) Object
Fig. 9 Test set-up

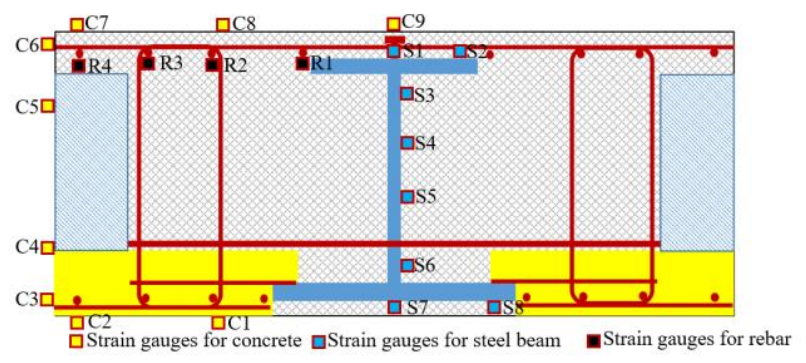

Fig. 10 Layout of the strain gauges at Section A-A (Fig. 9)

\section{Test results}

\subsection{Failure progression}

All four specimens displayed a flexural failure mode. Specimen 1 is chosen for detailed discussion hereafter. The initial crack on the bottom surface occurred at $30 \mathrm{kN}$. As the loading progressed, more cracks gradually developed. When $\mathrm{P}$ arrived at $165 \mathrm{kN}$, cracks spread to the filler with a slight sound heard. When $\mathrm{P}$ reached to $429 \mathrm{kN}$, the specimen yielded and a rapid growth of $U_{\text {mid }}$ occurred. The crushing of concrete in the compressive zone was observed when $U_{\text {mid }}$ was $88 \mathrm{~mm}$. In all tested specimens, the slippage between the RC slab and steel beam was observed to be relatively small and no damage of PBL was observed after removing its surrounding concrete, which demonstrates the effectiveness of the shear connectors adopted in this study. Additionally, there was no crack or separation between the precast concrete and CIP concrete throughout the experiment. Typical failure modes are shown in Fig. 11.

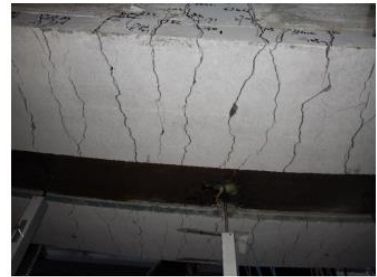

(a) Transverse cracks on bottom surface

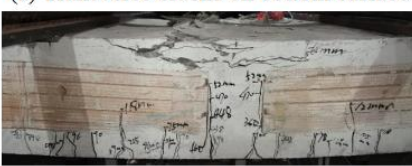

(c) Transverse cracks on side surface
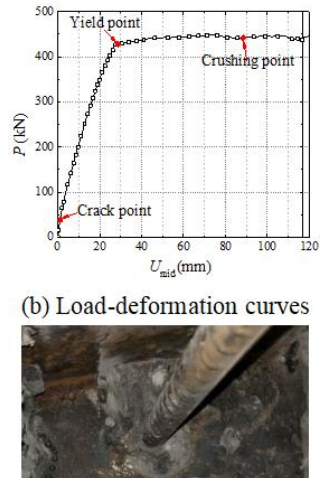

(d) PBL (b) Load-deformation curves

Fig. 11 Typical failure progression

\subsection{Load-deformation curve}

Fig. 12(a) shows the effect of shear connectors on the flexural behavior of the composite beam, indicating that the web openings can be an effective alternative to the shear studs. The effect of circular holes in Beam-C on the $P$ $U_{\text {mid }}$ curves is shown in Fig. 12(b). The load versus deformation curves show little difference between Specimen 3 and Specimen 4, suggesting that the diameter of circular holes has little influence on the flexural behavior of the composite beam. Fig. 12(c) shows the effect of loading conditions on the $P-U_{\text {mid }}$ curves, revealing that the composite beam under the sagging moment has a higher bending capacity and larger stiffness. This is mainly caused by the asymmetric steel beam.

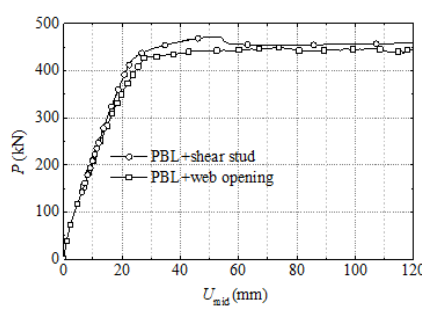

(a) Shear connectors

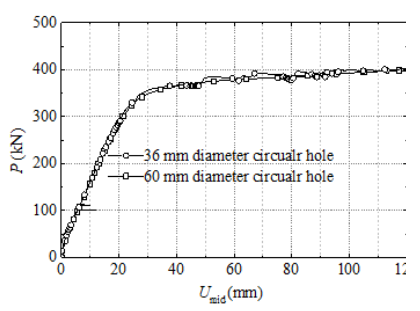

(b) Circular holes in Beam-C

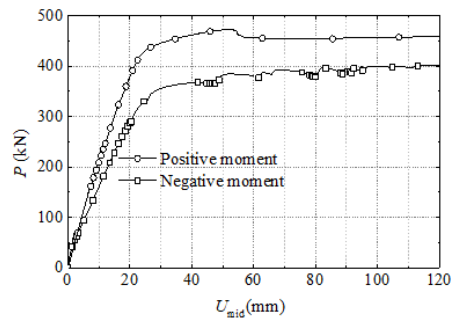

(c) Loading conditions

Fig. 12 Effects of experimental parameters on $P-U_{\text {mid }}$ curves

\subsection{Strain distributions}

The load versus strain of steel beam is illustrated in Fig. 13. As shown, the yield load of specimen $\left(P_{\mathrm{y}}\right)$ was attained when the strain at bottom beam flange (S7 and S8) reached the yield strain. With an increase in load, the strain in the beam web (S3, S4, S5, and S6) entered into the yield condition. The peak load $(\mathrm{Pu})$ was finally attained when the strain at top beam flange (S1 and S2) reached the yield strain. It can be stated that the plastic neutral axis of composite slim beam was near the top flange of steel beam. The strains along the beam height are approximately linearly distributed (Fig. 14), implying that Bernoulli' s assumption of plane-remain-plane can be preserved. The load versus strain of rebars is shown in Fig. 15. The rebars at the top of beam (R1, R2, R3 and R4) consistently remained elastic before $\mathrm{Pu}$ was attained. The strains of rebars corresponding to $0.25 P_{\mathrm{y}}, 0.50 P_{\mathrm{y}}$, and $P_{\mathrm{y}}$ are shown in Fig. 16, which shows evenly distributed strains across the beam width for a certain section. The load versus strain of concrete is given in Fig. 17. The strains of concrete linearly 
increased before $P_{\mathrm{y}}$ was attained, beyond which there was a rapid growth of strains. The distribution of concrete strains along the beam height is shown in Fig. 14. The strains of concrete in the middle region consistently remained small during the entire test, as the continuity of concrete was disrupted by the fillers.

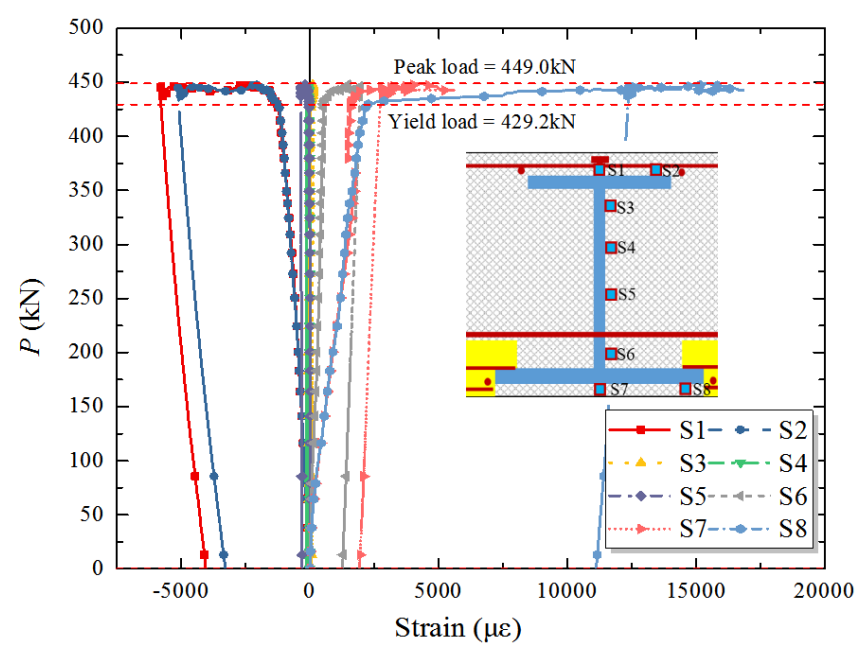

Fig. 13 Typical strains of steel beam

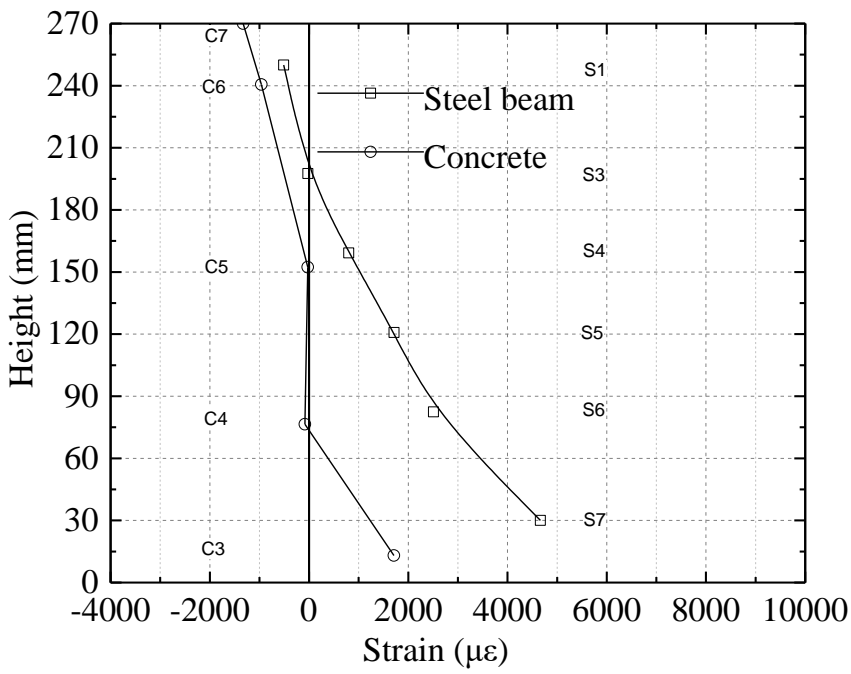

Fig. 14 Typical strain distributions along the beam height

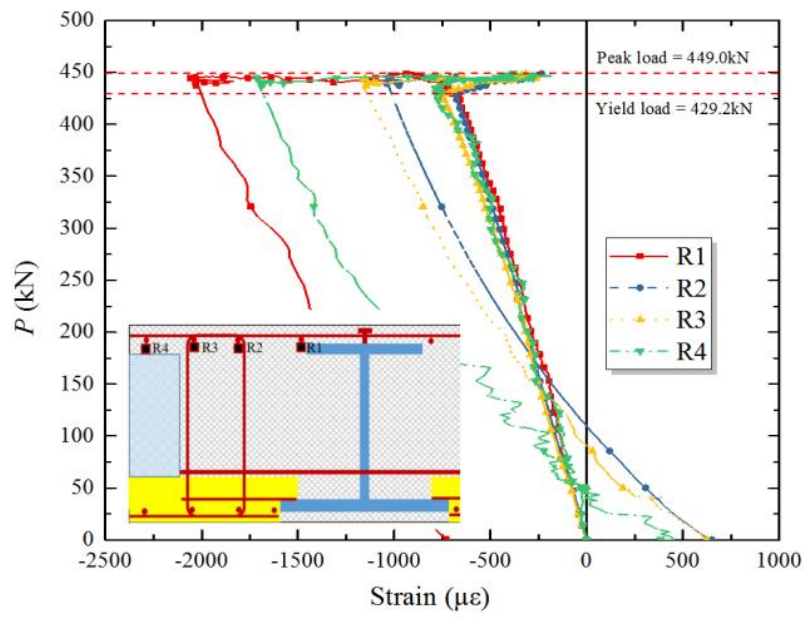

Fig. 15 Typical strains of rebars

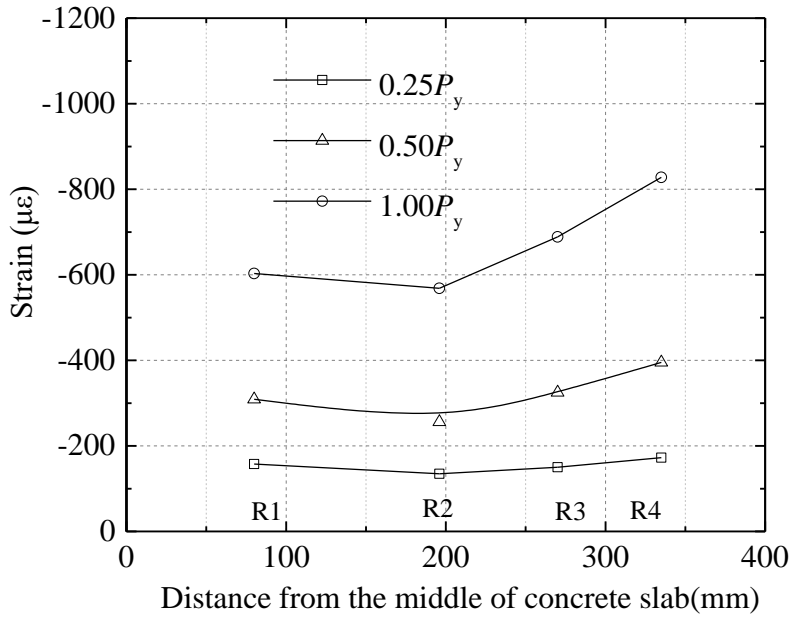

Fig. 16 Strains distributions of rebars along the beam width

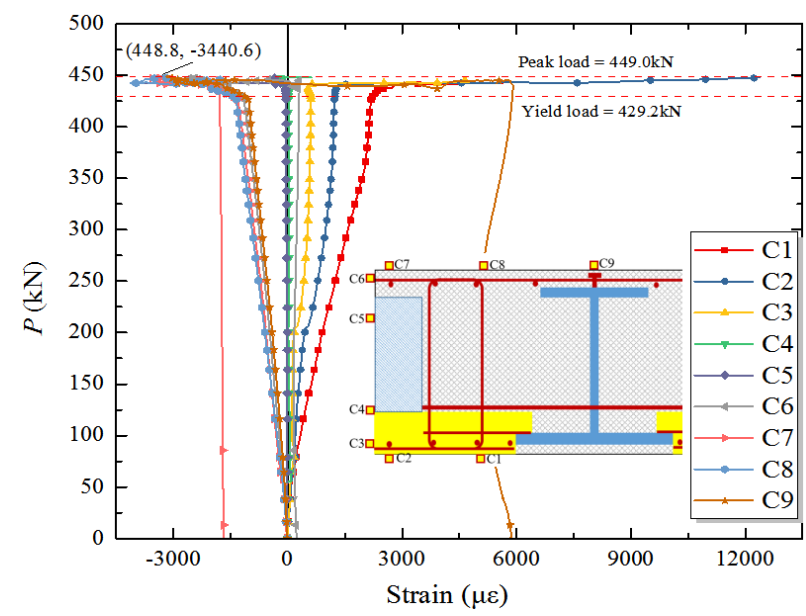

Fig. 17 Typical strains of concrete

\section{Finite element analysis}

A detailed finite element (FE) model was established using the FE program, ABAQUS [21], to investigate the flexural behavior of the composite beam.

\subsection{Materials}

\subsubsection{Steel}

For the steel beams and rebars, an elastic-perfectly plastic material was assumed in the FE model, in which the yield function $f\left(\sigma_{\mathrm{ij}}\right)$ of steel is expressed as

$f\left(\sigma_{\mathrm{ij}}\right)=\sqrt{3 J_{2}\left(\sigma_{\mathrm{ij}}\right)}-f_{\mathrm{s}}=0$

where $J_{2}$ is the second deviatoric stress invariant, $\sigma_{\mathrm{ij}}$ is the tensor of stress, and $f_{\mathrm{s}}$ is the yield strength of steel.

\subsubsection{Concrete}

The concrete damaged plasticity model defined in ABAQUS was adopted for the concrete material. Considering that the plastic behavior of concrete core has little effect on the flexural behavior of the composite beam, the stress-strain relationship for concrete as specified in the GB 50010-2010 [22] was adopted. For the concrete in tension, the $\sigma(\varepsilon)$ is given as

$\sigma(\varepsilon)= \begin{cases}\frac{n\left(\varepsilon / \varepsilon_{\mathrm{co}}\right) f_{\mathrm{co}}}{n-1+\left(\varepsilon / \varepsilon_{\mathrm{co}}\right)^{n}} & \left(\varepsilon / \varepsilon_{\mathrm{co}} \leq 1\right) \\ \frac{\left(\varepsilon / \varepsilon_{\mathrm{co}}\right) f_{\mathrm{co}}}{a_{\mathrm{c}}\left(\varepsilon / \varepsilon_{\mathrm{co}}-1\right)^{2}+\varepsilon / \varepsilon_{\mathrm{co}}} & \left(\varepsilon / \varepsilon_{\mathrm{co}}>1\right)\end{cases}$ 
concrete $\left(f_{\text {co }}\right)$ and $n$ and $\alpha_{\mathrm{c}}$ are the corrective coefficients for different concrete grades. For the concrete in tension, the $\sigma(\varepsilon)$ is described by

$$
\sigma(\varepsilon)= \begin{cases}E_{c} \varepsilon & \varepsilon \leq \varepsilon_{\mathrm{ct}} \\ \left.f_{\mathrm{ct}}-E_{\mathrm{ts}}\left(\varepsilon-\varepsilon_{\mathrm{ct}}\right)\right) & \varepsilon_{\mathrm{ct}}<\varepsilon\end{cases}
$$

where $f_{\mathrm{ct}}=0.1 f_{\mathrm{co}}$ and $\varepsilon_{\mathrm{ct}}=f_{\mathrm{ct}} / E_{\mathrm{c}}$ with $E_{\mathrm{c}}$ being the elastic modulus of concrete. The softening modulus $E_{\mathrm{ts}}$ being dependent of the mesh size was used to handle the concrete localization issue, which is given as

$E_{\mathrm{ts}}=f_{\mathrm{ct}}^{2} l_{\mathrm{c}} /\left(2 G_{\mathrm{f}}\right)$

where $l_{\mathrm{c}}$ is the mesh size and $G_{\mathrm{f}}$ is the fracture energy calculated according to CEB-FIP MC90 [23]. The $\sigma(\varepsilon)$ for concrete in both compression and tension is shown in Fig. 18.
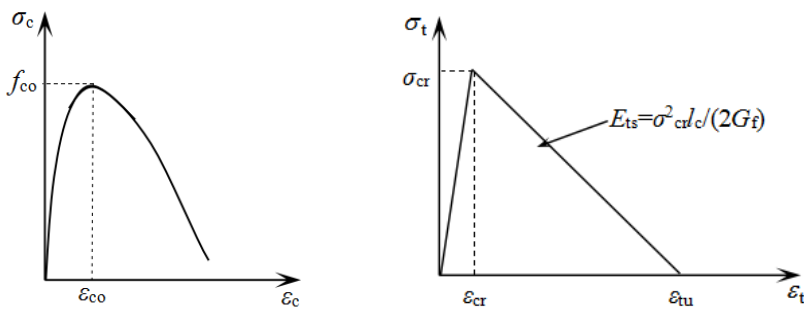

Fig. 18 Stress-strain curves of concrete

A detailed finite element (FE) model was established using ABAQUS [16] to investigate the flexural behavior of the composite beam. Typically, 4-noded shell elements with reduced integration (i.e., S4R elements) were used to represent the steel beam; 8-noded solid elements with reduced integration (i.e., C3D8R elements) were employed to simulate the concrete; and 2-noded truss elements (i.e., T3D2 elements) were used to represent the rebars. Both the steel beam and the rebars are assumed to be the elastic perfectly-plastic material in the FE model. Considering that the plastic behavior of concrete core has little effect on the flexural behavior of the composite beam, the stress-strain relationship for core concrete specified in the GB 50010-2010 [17] was adopted. The boundary conditions of FE model are depicted in Fig. 14. The rollers were simulated by the rigid body constraints tied to the surface of concrete slab.

\subsection{Element types, interface, mesh, and boundary conditions}

Solid elements were used to simulate the concrete. Shell elements and truss elements were employed to represent the steel beam and the rebars, respectively. The rebars were embedded in the concrete. Two extreme connection cases between the RC slab and steel beam were considered: fully-separated model (Model 1) and the complete-glued model (Model 2). In Model 1, the RC slab and steel beam were simulated separately, where the $P$ - $U_{\text {mid }}$ curves of RC slab and steel beam separately predicted by the FE model were simply added up. In Model 2, the steel beam was embedded in the concrete. A sensitivity study on the mesh size was performed, concluding the element mesh size of $60 \mathrm{~mm}$ which yields the predicted results with a relative error of $1 \%$ only. The boundary conditions of the FE model are depicted in Fig. 19, where the rollers were simulated using the rigid body constraints that are tied to the surface of concrete slab.

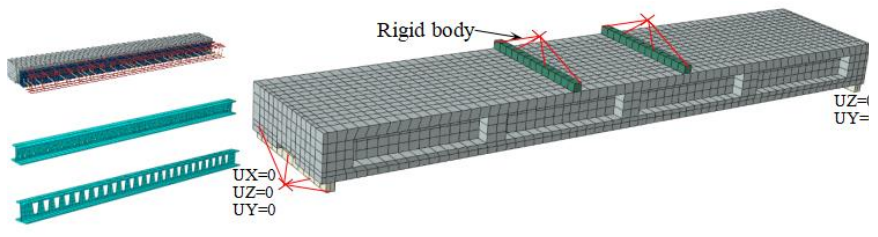

Fig. 19 Details for the FE model

\subsection{FE analysis}

Two extreme connection cases between the RC slab and steel beam were considered: fully-separated model (Model 1) and complete-glued model (Model $2)$. The $P$ - $U_{\text {mid }}$ curves predicted by the FE model are compared with the experimental ones, as shown in Fig. 20. As seen, the experimental results are generally in good agreement with the results predicted by Model 2, suggesting that the RC slab works well with the steel beam. Therefore, the full interaction between the RC slab and steel beam can be considered.

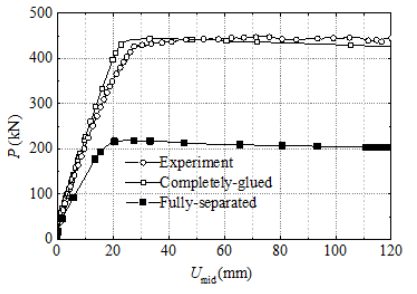

(a) Specimen 1

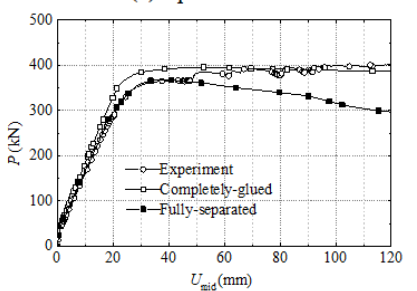

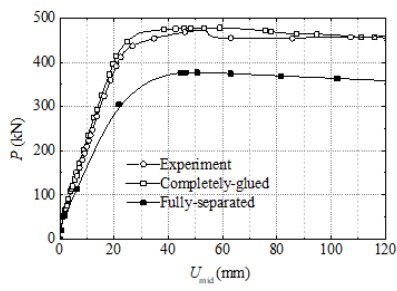

(b) Specimen 2

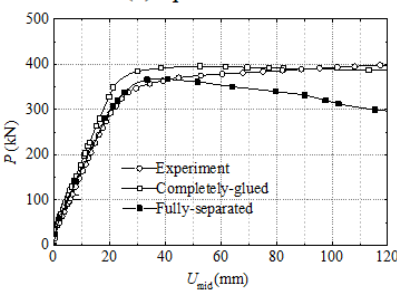

$U_{\text {mito }}(\mathrm{mm})$
Fig. 20 Comparisons of $P-U_{\text {mid }}$ curves

As a representative case, Specimen 1 is selected for further discussion. The failure modes of Specimen 1 predicted by the FE model are shown in Fig. 21. As seen, severe damage prevails in the pure bending zone, which is consistent with the experimental observation. The steel beam and rebars yield at the end of the test, indicating an adequately reinforced composite beam. All the PBL is consistently elastic, demonstrating a full interaction between the RC slab and steel beam.

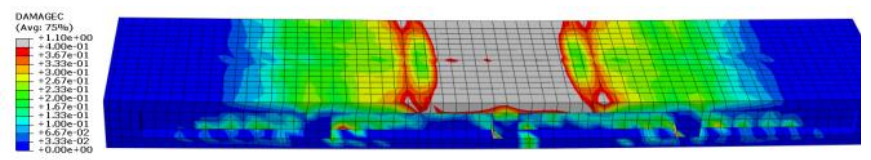

(a) Damage of concrete in compression

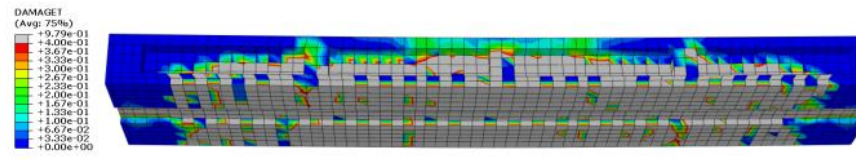

(b) Damage of concrete in tension

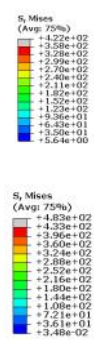

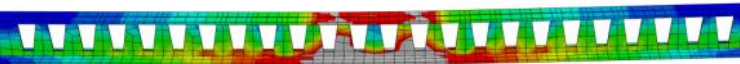

(c) volp Mises stress contour of steel beam

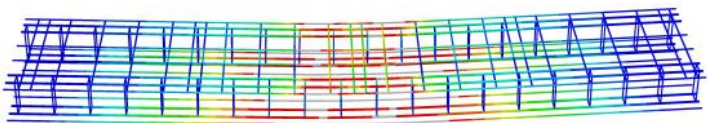

(d) von Mises stress contour of rebars
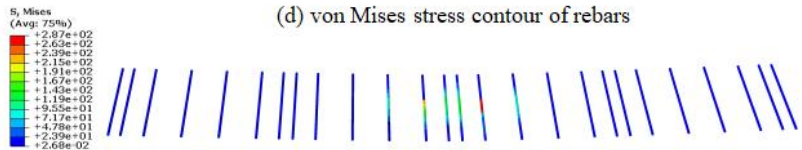

Fig. 21 Results predicted by the FE model

\section{Proposed design method}

The bending capacity of each specimen was determined according to the American Institute of Steel Construction Specification [2], which assumes that: (a) The distribution of strains along the section complies with the assumption of 
plane-remain-plane and the compression strains are uniformly distributed across the cross-section at a specific level; (b) The stress of concrete in the tensile region is negligible; and (c) The concrete works well with the steel beam and longitudinal rebars. Note that these assumptions have been validated by tests. The strain and stress distributions under the full interaction condition are shown in Fig. 22. The plastic neutral axis (PNA) is likely to be located at one of the following positions: in the filler (PNA-1); between the filler and top steel beam flange (PNA-2); and in the top steel beam flange (PNA-3). As an example, PNA-2 is determined by

$C_{1}+T_{2}+T_{4}=T_{1}+T_{3}+T_{5}$

where $C_{1}$ is the compressive force in the concrete, $T_{1}$ is the tensile force in the steel beam flange, $T_{2}$ is the compressive force in the steel beam flange, $T_{3}$ is the tensile force of the longitudinal rebars, $T_{4}$ is the compressive force in the longitudinal rebars, and $T_{5}$ is the tensile force of the steel beam web. The notation in Fig. 22 is as follows: $f_{\mathrm{c}}$ is the axial compressive strength of concrete; $f_{\mathrm{s}}$ is the yield strength of steel beam; $f_{\mathrm{b}}$ is the yield strength of longitudinal rebars; $A_{\mathrm{fb}}$ is the cross-sectional area of the steel beam flange in tension; $A_{\mathrm{sb}}$ is the crosssectional area of the longitudinal rebars in tension; $A_{\mathrm{ft}}$ is the cross-sectional area of the steel beam flange in compression; $A_{\mathrm{st}}$ is the cross-sectional area of the longitudinal rebars in compression; $A_{\mathrm{w}}$ is the cross-sectional area of the steel beam web in tension; $b_{\mathrm{c}}$ is the width of composite beam; $h_{1}$ is the distance between the extreme compression fiber and the centerline of top beam flange; and $x$ is the distance between the extreme compression fiber and PNA. Due to the sectional properties of the composite beam, the PNA is generally near the top flange of steel beam. Since the thickness of beam flange is quite small, the PNA may be considered at the centerline of top beam flange for simplification (i.e., $x=h_{1}$ ). As such, the bending capacity $M_{\text {cal }}$ can be calculated by

$M_{\text {cal }}=T_{1} \times y_{1}+T_{3} \times y_{3}+T_{5} \times y_{5}+T_{4} \times y_{4}+0.85 f_{\mathrm{c}} b_{\mathrm{c}} h_{1}\left(h_{1}-0.85 h_{1} / 2\right)$

where $y$ is the distance between the PNA and the centroid of the resultant force. The comparison between the calculated and measured bending capacities $\left(M_{\text {cal }}\right.$ and $M_{\mathrm{u}}$ ) is given in Table. 4. As indicated, the proposed design method is acceptable.

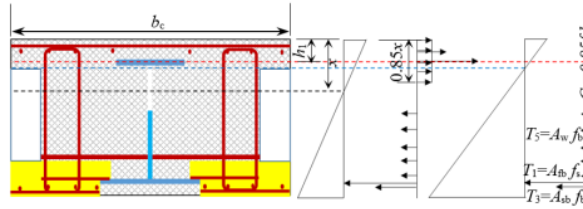

(a) PNA-1 (b) PNA-2

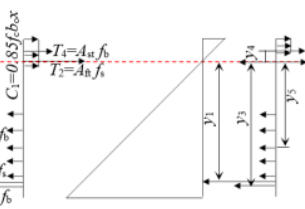

(c) PNA-3
Fig. 22 Strain and stress distributions under the full interaction condition

Table 4

Comparison between the calculated and measured bending capacities

\begin{tabular}{cccc}
\hline Specimen label & $M_{\mathrm{cal}}(\mathrm{kN} \cdot \mathrm{m})$ & $M_{\mathrm{u}}(\mathrm{kN} \cdot \mathrm{m})$ & $M_{\mathrm{cal}} / M_{\mathrm{u}}(\mathrm{kN} \cdot \mathrm{m})$ \\
\hline Specimem-1 & 332 & 337 & 0.99 \\
Specimem-2 & 360 & 354 & 1.02 \\
Specimem-3 & 285 & 299 & 0.95 \\
Specimem-4 & 283 & 295 & 0.96 \\
\hline
\end{tabular}

\section{Conclusions}

This paper describes and discusses the bending behavior of a new composite slim floor system, based on an experimental study on four specimens. The following major findings are offered based on the results from this pilot study:

(1) The full interaction between the RC slab and steel beam can be achieved by the beam web openings as they act as effective shear connectors.

(2) The diameter of circular holes drilled on steel beam web has little influence on the flexural behavior of composite slim beam within the range of parameters considered in this study.

(3) Bernoulli's assumption of plane-remain-plane is maintained for the proposed composite slim beam. Due to the sectional properties of proposed composite slim beam, the plastic neutral axis is generally near the top flange of steel beam.
(4) The proposed design method for estimating the bending capacity of proposed composite slim beam is convenient and acceptable. Further studies on bending capacity and shear capacity are suggested for improving the design method, however.

\section{Nomenclature}

$A_{\mathrm{fb}} \quad$ cross-sectional area of the steel beam flange in tension

$A_{\mathrm{ft}} \quad$ cross-sectional area of the steel beam flange in compression

$A_{\mathrm{sb}} \quad$ cross-sectional area of the longitudinal rebars in tension

$A_{\text {st }} \quad$ cross-sectional area of the longitudinal rebars in compression

$A_{\mathrm{w}} \quad$ cross-sectional area of the steel beam web in tension

$b_{\mathrm{c}} \quad$ width of composite beam

$C_{1} \quad$ compressive force in the concrete

$E_{\mathrm{c}} \quad$ elastic modulus of concrete

$E_{\mathrm{ts}} \quad$ softening modulus

$f_{\mathrm{b}} \quad$ yield strength of longitudinal rebars

$f_{\mathrm{c}} \quad$ axial compressive strength of concrete

$f_{\text {co }} \quad$ axial compressive strength of concrete

$f_{\mathrm{s}} \quad$ yield strength of steel beam

$f_{\text {ct }} \quad$ tensile strength of concrete

$G_{\mathrm{f}} \quad$ fracture energy

$h_{1} \quad$ distance between extreme compression fiber and centerline of top beam flange

$J_{2} \quad$ second deviatoric stress invariant

$l_{\mathrm{c}} \quad$ mesh size

$n \quad$ first corrective coefficient for different concrete grades

$M_{\text {cal }} \quad$ calculated bending capacity

$M_{\mathrm{u}} \quad$ measured bending capacity

$P \quad$ load applied on the loading beam

$P_{\mathrm{y}} \quad$ yield load applied on the loading beam

$P_{\mathrm{u}} \quad$ peak load applied on the loading beam

$T_{1} \quad$ tensile force in the steel beam flange

$T_{2} \quad$ compressive force in the steel beam flange

$T_{3} \quad$ tensile force of the longitudinal rebars

$T_{4} \quad$ compressive force in the longitudinal rebars

$T_{5} \quad$ tensile force of the steel beam web

$U_{\text {mid }}$ displacement of the composite beam at mid-span

$x \quad$ distance between the extreme compression fiber and the plastic neutral axis

$y \quad$ distance between the plastic neutral axis and the centroid of resultant force

$\alpha_{\mathrm{c}} \quad$ second corrective coefficient for different concrete grades

$\varepsilon_{\mathrm{ct}} \quad$ strain corresponding to the tensile strength of concrete

$\varepsilon_{\mathrm{co}} \quad$ strain corresponding to the axial compressive strength of concrete

$\sigma(\varepsilon) \quad$ equivalent stress-strain relationship of concrete

$\sigma_{\mathrm{ij}} \quad$ tensor of stress

\section{Acknowledgments}

The authors greatly appreciate the financial support provided by the National Key R\&D Program of China (No. 2016YFC0701201) and the National Natural Science Foundation of China (No. 51408620).

\section{References}

[1] An Q, Ren Q, Liu H, Yan XY, Chen ZH. Dynamic performance characteristics of an innovative cable supported beam structure-concrete slab composite floor system under human-induced loads[J]. Engineering Structures, 2016, 117: 40-57.

[2] Tian L M, Kou Y F, Hao J P, Zhao L W. Flexural performance of a lightweight composite floor comprising cold-formed steel trusses and a composite mortar slab[J]. Thin-Walled Structures, 2019, 144: 106361

[3] de Seixas Leal L A A, de Miranda Batista E. Experimental investigation of composite floor system with thin-walled steel trussed beams and partially prefabricated concrete slab[J]. Journal of Constructional Steel Research, 2020, 172: 106172.

[4] Pang R, Zhang Y B, Dang L J, Liang S T. Experimental and numerical investigation on the vertical bearing behavior of discrete connected new-type precast reinforced concrete floor system[J]. Advances in Structural Engineering, 2020: 1369433220911141.

[5] Eurocode 4: Design of composite steel and concrete structures, Part 1.1, general rules and rules for Building. London: British Standards Institution; 2004 (BS EN 1994-1-1: 2004).

[6] ANSI/AISC 341-10. Seismic provisions for structural steel buildings. Chicago, Illinois, USA American Institute of Steel Construction; 2010.

[7] Mullett D L. Slim floor design and construction[M]. UK: Steel Construction Institute, 1992.

[8] Lawson R M, Mullett D L, Rackham J W. Design of asymmetric slimflor beams using deep composite decking[M]. Berkshire: Steel Construction Institute, 1997.

[9] Bailey C G. The behaviour of asymmetric slim floor steel beams in fire[J]. Journal of Constructional Steel Research, 1999, 50(3): 235-257

[10] Ma Z, Mäkeläinen P. Behavior of composite slim floor structures in fire[J]. Journal of Structural Engineering, 2000, 126(7): 830-837.

[11] Lu X H, Makelainen P. Strength and stiffness of composite slim floor beams[C]. Proceedings of the 4st Pacific structural steel conference, 1995

[12] Malaska M. Behaviour of a semi-continuous beam-column connection for composite slim floors[M]. Helsinki University of Technology, 2000.

[13] Bernuzzi C, Gadotti F, Zandonini R. Semi-continuity in slim floor steel-concrete composite systems[C]//1st European Conference on Steel Structures, Athens, Greece. 1995.

[14] De Nardin S, El Debs A L H C. Study of partially encased composite beams with innovative 
position of stud bolts[J]. Journal of Constructional Steel Research, 2009, 65(2): 342-350.

[15] Hosseinpour E, Baharom S, Badaruzzaman W H W, Al Zand A W. Push-out test on the web opening shear connector for a slim-floor steel beam: Experimental and analytical study[J]. Engineering Structures, 2018, 163: 137-152

[16] Maraveas C, Swailes T, Wang Y. A detailed methodology for the finite element analysis of asymmetric slim floor beams in fire[J]. Steel Construction, 2012, 5(3): 191-198.

[17]Ahn J K, Lee C H. Fire behavior and resistance of partially encased and slim-floor composite beams[J]. Journal of Constructional Steel Research, 2017, 129: 276-285.

[18] Ryu J, Ju Y K, Yoon S W, et al. Bending capacities of glass fibre reinforced plastic composite slab[J]. Materials Research Innovations, 2013, 17(sup2): s12-s18.

[19] Ryu J, Lee C H, Oh J, et al. Shear resistance of a biaxial hollow composite floor system with GFRP plates[J]. Journal of Structural Engineering, 2016, 143(2): 04016180

[20] Ryu J, Lee C H, Oh J, Yoon S W, Ju Y K. Shear resistance of a biaxial hollow composite floor system with GFRP plates[J]. Journal of Structural Engineering, 2017, 143(2): 04016180. [21] Hibbitt, Karlsson, Sorensen. ABAQUS/Standard User's Manual. Version 6.7.1, Hibbitt, Karlsson \& Sorensen, Inc., 2007.

[22] GB 500010-2010. Code for design of concrete structures; 2010 [in Chinese].

[23] Design of concrete structures. CEB-FIP-Model-Code 1990. British Standard Institution, London, 1993. 